\title{
HeLM: a macrophyte-based method for monitoring and assessment of Greek lakes
}

\author{
Dimitrios Zervas • Vasiliki Tsiaoussi • \\ Ioannis Tsiripidis
}

Received: 6 November 2017 / Accepted: 26 April 2018/Published online: 5 May 2018

(C) The Author(s) 2018

\begin{abstract}
The Water Framework Directive (WFD) requires Member States to develop appropriate assessment methods for the classification of the ecological status of their surface waters. Mediterranean region has lagged behind in this task, so we propose here the first developed method for Greek lakes, Hellenic Lake Macrophyte (HeLM) assessment method. This method is based on two metrics, a modified trophic index and maximum colonization depth $C_{\max }$ that quantify the degree of changes in lake macrophytic vegetation, as a response to eutrophication and general degradation pressures. The method was developed on the basis of a data set sampled from 272 monitoring transects in 16 Greek lakes. Sites from three lakes were selected as potential reference sites by using a screening process. Ecological quality ratios were calculated for each metric and for each lake, and ecological status class boundaries were defined. For the evaluation of effectiveness of the method, the correlations between individual metrics and final HeLM values and common pressure indicators,
\end{abstract}

Electronic supplementary material The online version of this article (https://doi.org/10.1007/s10661-018-6708-1) contains supplementary material, which is available to authorized users.

D. Zervas · V. Tsiaoussi

The Goulandris Natural History Museum - Greek Biotope / Wetland Centre, 14th km Thessaloniki-Mihaniona, Thermi, P.O. Box 60394, 57001 Thessaloniki, Greece

D. Zervas $(\bowtie) \cdot$ I. Tsiripidis

Department of Botany, School of Biology, Aristotle University of Thessaloniki, GR-54124 Thessaloniki, Greece

e-mail: dzervas@ekby.gr such as total phosphorus, chlorophyll $a$ and Secchi depth, were tested and found highly significant and relatively strong. In addition, the ability of HeLM values and its individual metrics to distinguish between different macrophytic communities' structure was checked using aquatic plant life-forms and found satisfactory. The HeLM method gave a reliable assessment of the macrophytic vegetation's condition in Greek lakes and may constitute a useful tool for the classification of ecological status of other Mediterranean lakes.

Keywords Macrophytes · Greek lakes · Ecological status $\cdot$ Reference conditions $\cdot$ Class boundaries $\cdot$ Water Framework Directive

\section{Introduction}

The Water Framework Directive (WFD; European Commission 2000) supervises the monitoring and assessment of the ecological status of surface waters within the EU. One of the main aims of the Directive is the development of ecological assessment methods for different groups of organisms (biological quality elements (BQEs), i.e., phytoplankton, macrophytes and phytobenthos, macroinvertebrates, fish) for aquatic ecosystems (lakes, rivers, transitional waters, and coastal waters) (European Commission 2003a). These methods need to classify the ecological status of surface waters at a five-level ecological classification scheme, indicating the degree of deviation from reference conditions (European Commission 2003a). 
Aquatic macrophytes are commonly used in classification systems in lakes as they play a significant role in determining the structure and functions of lake ecosystems, by altering environmental conditions, nutrient cycling, biotic assemblages, and interactions (Engelhardt and Ritchie 2001; Spoljar et al. 2017; Wang et al. 2009). Moreover, their time of response to changes in nutrient conditions in a water body lies between the fastresponsive phytoplankton and phytobenthos organisms and the slow-responsive invertebrates and fish, which makes them valuable bioindicators, when monitoring the ecological quality of water bodies (Pall and Moser 2009; Penning et al. 2008a, b; Schneider and Melzer 2003). Sunlight penetration and availability are important factors for the development of submerged macrophytes and explain greater than half of the variation in macrophyte composition and abundance (De Boer 2007). Loss of macrophytic vegetation has been experienced in many lakes around the world during the last century due to the increase in the availability of nutrients in the water column that led to a rapid growth of phytoplankton, which in turn caused an increase in water turbidity and a decrease in sunlight penetration and availability (Blindow et al. 2006; Hilt et al. 2006).

After the publication of WFD, most Member States (MS) have focused efforts to develop WFD-compliant aquatic macrophyte methods to assess the ecological status of lakes (Birk et al. 2012; Poikane et al. 2015). However, there are still gaps in the Mediterranean region, as a reflection of different monitoring traditions in comparison to Central and Northern European countries (Birk et al. 2012). More specifically, with regard to natural lakes, MS in the Mediterranean region encountered difficulties in the development of their ecological assessment methods due to the small number and high variability of natural lakes, as well as the limited data availability (Poikane et al. 2015). Another important reason for this time-lag in the monitoring and assessment research in the Mediterranean region is the substantial differences between warm Mediterranean lakes and colder temperate ones (Alvarez Cobelas et al. 2005; Beklioglu et al. 2007). The Mediterranean climate is characterized by a strong seasonality of rainfall and air temperature, whereas rainfall occurs mostly in spring and autumn (Alvarez Cobelas et al. 2005). According to Hoerling et al. (2012), the land area surrounding the Mediterranean Sea has experienced 10 of the 12 driest winters since 1902 in just the last 20 years. Correspondingly, water shortages and droughts are not uncommon in many Mediterranean areas. As a result, Mediterranean lakes experience continuous intra-annual and interannual water-level fluctuations which render them a type of aquatic ecosystems under constant alterations (Özen et al. 2010). All the above add to the necessity for the development of a complete lake assessment method based on aquatic macrophytes for the Mediterranean region.

In this study, we overcome this gap and we present the newly developed ecological assessment method named as Hellenic Lake Macrophyte assessment method (HeLM) for classification of Greek lakes. In particular, the development of this method was grounded in (a) the collection of macrophyte and environmental data from natural lakes of the Greek National Water Monitoring Network, (b) the definition of type-specific reference conditions for aquatic macrophytes, (c) the use of appropriate metrics to calculate the deviation of each lake's ecological status from reference conditions, and (d) the setting of status class boundaries. The result is an assessment method that can address changes in the ecological status of lakes due to eutrophication and general degradation pressures, in compliance with WFD requirements.

The aims of this study are (a) to describe the rationale and the application of the HeLM method, (b) to test its effectiveness to assess the ecological status of Greek natural lakes, and (c) to discuss its limitations and needs for further improvements in the future.

\section{Materials and methods}

Study area

The Greek National Water Monitoring Network became operational in 2012. In total, 50 lake water bodies (including 24 natural lakes and 26 reservoirs) have been included in the network. Sixteen lakes have been monitored for aquatic macrophytes during 2013-2015 (Fig. 1 and Table 1). According to ETC/ICM (2015), they all belong into the Mediterranean lake types. In particular, eight of them are warm monomictic, deep natural lakes with mean depth $>9 \mathrm{~m}$ (national type GR-DNL) and eight are polymictic, shallow natural lakes with mean depth 3-9 m (national type GR-SNL). From the eight GR-DNL type lakes, Feneos lake (no. 15) is a reservoir constructed for irrigation purposes. However, since the irrigation network has not been constructed, water level 
Fig. 1 Lakes in the Greek National Water Monitoring Network for which macrophytic data were acquired. See Table 1 for lake names

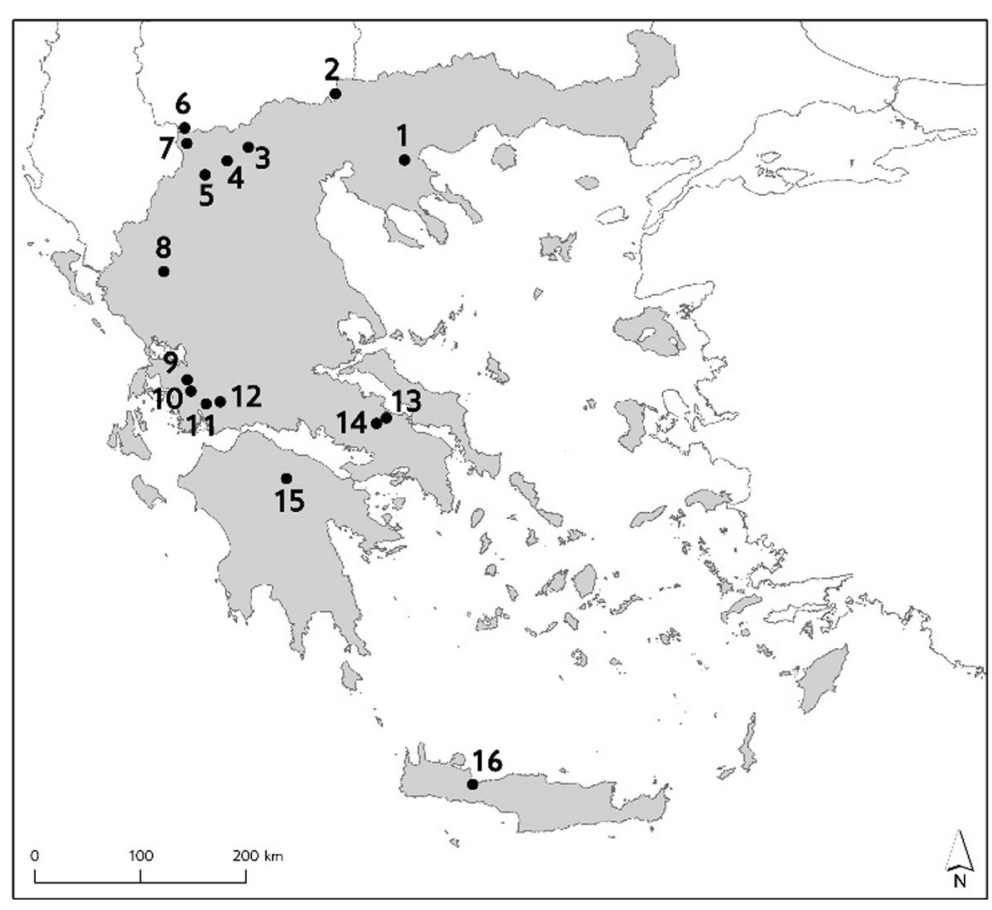

fluctuates only due to natural conditions; therefore, a species-rich and abundant aquatic vegetation has been developed to such an extent that lake Feneos resembles ecologically a natural lake.

Table 1 Sampling period and number of transects established for the investigation of the macrophytic vegetation, in the 16 lakes of the Greek National Monitoring Network

\begin{tabular}{|c|c|c|c|c|c|}
\hline No. & Lake & Abbreviation & Type & No. of transects & Sampling period \\
\hline 1 & Volvi & VOL & GR-DNL & 20 & September 2013 \\
\hline 2 & Doirani* & DOI & GR-SNL & 10 & August 2013 \\
\hline 3 & Vegoritida & VEG & GR-DNL & 20 & August 2013 \\
\hline 4 & Zazari & $\mathrm{ZAZ}$ & GR-SNL & 12 & August 2015 \\
\hline 5 & Kastoria & KAS & GR-SNL & 20 & August 2014 \\
\hline 6 & Megali Prespa* & MEP & GR-DNL & 12 & August 2015 \\
\hline 7 & Mikri Prespa* & MIP & GR-SNL & 15 & August 2015 \\
\hline 8 & Pamvotida & PAM & GR-SNL & 20 & September 2013 \\
\hline 9 & Amvrakia & AMV & GR-DNL & 20 & June 2014 \\
\hline 10 & Ozeros & OZE & GR-SNL & 20 & June 2014 \\
\hline 11 & Lysimachia & LYS & GR-SNL & 20 & June 2014 \\
\hline 12 & Trichonida & TRI & GR-DNL & 20 & July 2015 \\
\hline 13 & Paralimni & PAR & GR-SNL & 19 & July 2014 \\
\hline 14 & Yliki & YLI & GR-DNL & 20 & July 2014 \\
\hline 15 & Feneos & FEN & GR-DNL & 10 & August 2014 \\
\hline 16 & Kourna & $\mathrm{KOU}$ & GR-DNL & 14 & May 2014 \\
\hline Total & & 16 lakes & 2 types & 272 & 3 -year period \\
\hline
\end{tabular}

GR-DNL type are warm monomictic, deep natural lakes with mean depth $>9$ m while GR-SNL type are polymictic, shallow natural lakes with mean depth 3-9 m. Transboundary lakes that only the part of their surface area in Greece was surveyed are marked with asterisks 
Sampling

In all 16 lakes, the belt transect-mapping method was applied. It is the most commonly applied method for aquatic vegetation surveys and monitoring in many European countries and it is also recommended by the European Committee for Standardization (CEN), as it provides at the same time abundance, frequency, and depth distribution data of different species in a lake (Kolada et al. 2009).

The number and location of transects were selected using the Jensen's method (1977), bathymetric data, habitat maps, and land use maps for the lakes and their catchment area. Four different groups of riparian habitat types were distinguished around each lake, using the classification scheme of XP T90-328 (2010) Standard. In each group, at least three transects were established. This number was increased in cases of high variability (e.g., ecological, morphological, hydrological reasons) within each group of riparian habitat types. The final number of transects in each lake ranged from 10 to 20 . In total, 272 transects were established (Table 1).

Sampling within each transect followed the guidelines proposed by I.S. EN 15460 (2007) and Kolada et al. (2009). Transects were perpendicular to the lake shoreline and represented a strip area from the shoreline to the maximum depth of plant growth. The strip area had a width of ca. $5 \mathrm{~m}$ to enable boat maneuvering and the handling of the sampling tools. Sampling was conducted in five depth zones: $0-1,1-2,2-4,4-8 \mathrm{~m}$, and > $8 \mathrm{~m}$ (Janauer 2002) by means of a double-headed rake with a scaled handle or attached to a rope, a bathyscope, and a geo-bathymetric device. In each depth zone, five plots, evenly distributed along the increasing depth gradient, were sampled. All angiosperms (helophytes, hydrophytes, amphiphytes, and aquatic forms of land species), pteridophytes, bryophytes, charophytes, and other green filamentous macroalgae (e.g., Cladophora spp.) were recorded in each plot, and their abundance was estimated by using the semi-quantitative five-point DAFOR scale (Palmer et al. 1992). Angiosperms, pteridophytes, bryophytes, and charophytes were determined to the species or subspecies level by using suitable floras and identification keys (Online Resource, Supplement 1).

Furthermore, for each transect, the maximum colonization depth of aquatic macrophytes $\left(C_{\max }\right)$ was recorded. To ensure its proper measurement, at the end of each transect, more than one plots with no vegetation were sampled. At each lake, three transects with larger $C_{\max }$ values were revisited annually during the 3 -year period. Thus, 36 transects were revisited, and in total, 308 measurements of $C_{\max }$ at transect level were made.

Environmental data indicating eutrophication pressure were also collected during the 3 -year sampling period. In each lake, two to three monthly samples for chlorophyll $a$ (CHLA) and Secchi depth (SD) measurements were taken during each summer season (June to August). Samplings for total phosphorus (TP) were seasonal for each year. Water samples were taken at the deepest part of the lakes, from the euphotic zone $(2.5 \times$ SD depth) by using either an integrated-type or a Nansen-type sampler (de Hoyos et al. 2014). TP was determined with persulfate digestion (Rice et al. 2012) and CHLA by using $90 \%$ acetone and applying the trichromatic equation (Rice et al. 2012; Jeffrey and Humphrey 1975). Land use data for the catchment area of each lake was acquired by Corine Land Cover (CLC) 2012, version 18.5.1 (Copernicus Service-Pan-European Component 2012). Population data were acquired by the 2011 Population-Housing Census (Hellenic Statistical Authority 2011).

Development of the HeLM assessment method

\section{Rationale for metric selection}

According to WFD requirements, ecological status assessment based on aquatic macrophytes should take into consideration both their taxonomic composition and abundance (European Commission 2000). Existing taxonomic composition metrics vary from simple ones, such as diversity indices (total number of taxa or number of submerged taxa, etc.), proportions of different functional groups of species (relative coverage of charophytes, isoetids, etc.), to more complex ones based on each species' sensitivity to disturbance represented by scores, such as trophic indices, indicator species, and sensitive/tolerant taxa (Birk 2010; Birk et al. 2012; Poikane et al. 2015). For the measurement of abundance, the most widely used metric is $C_{\max }$, which simply expresses the maximum observed depth of a lake where submerged rooted macrophytes are present (Birk 2010; Poikane et al. 2015). $C_{\max }$ is considered as a very useful measure of total macrophyte abundance in lakes, being tightly connected to water transparency and thus to trophic state (Pall and Moser 2009). It responds quickly to changes of water quality (Mehner et al. 
2008) and its assessment is quite unbiased (Willby et al. 2009). $C_{\max }$ values can range from zero meters in hypereutrophic lakes with no submerged aquatic vegetation to many meters of depth in oligotrophic lakes with extensively developed submerged vegetation. In very shallow lakes, where there is not a depth limit of macrophytic growth, the relative mean percent of macrophyte coverage of total lake area is used instead (Birk 2010; Kolada 2014; Poikane et al. 2015).

The response of the most common macrophyte metrics in eutrophication gradients in lakes was explored and tested by Dudley et al. (2011), Kolada et al. (2011), and Kolada et al. (2014). Their results signified that indices based on trophic scores perform better, with the Intercalibration Common Metric for lake macrophytes $\left(\mathrm{ICM}_{\mathrm{LM}}\right)$ being the best performer, followed by Ellenberg Index (EI). Species richness metrics (number of taxa and number of submerged taxa) responded weakly to eutrophication gradients, while the metrics based on proportions of functional groups responded differently in ecosystems of lower and higher trophy, weakening their diagnostic value. For the abundance metrics, it was found that both $C_{\max }$ and the coverage of aquatic macrophytes respond significantly to eutrophication stressors. The former metric was recommended for use in lakes with mean depth $>3 \mathrm{~m}$ and the latter in very shallow lakes (mean depth $<3 \mathrm{~m}$ ) (Kolada et al. 2011; Kolada 2014).

During the development of the HeLM assessment method, we tested the above-mentioned metrics in various combinations, for their response to eutrophication pressure with data from the Greek Monitoring Network. We found that $\mathrm{ICM}_{\mathrm{LM}}$ and $C_{\max }$ were the bestperforming ones; thus, HeLM assessment method was designed using these two metric components.

\section{Trophic index HeLM}

The trophic index metric HeLM (TIHeLM) we applied is a modified form of $\mathrm{ICM}_{\mathrm{LM}}$, which is based on taxonspecific trophic scores (lake trophic ranks (LTRs)), originally developed for the purpose of the WFD intercalibration exercise for lakes (Hellsten et al. 2014; Kolada et al. 2011, 2014). $\mathrm{ICM}_{\mathrm{LM}}$ had to be modified in order to be more effective in evaluating the eutrophication pressure in Mediterranean-type lakes. Three modifications were made concerning the calculation of (a) the LTRs for taxa not included in Kolada et al. (2011, 2014), (b) the weighted average of LTRs per transect by using species cover as weight, and (c) the trophic index of each lake by averaging the corresponding index values of the transects sampled in the lake.

In Kolada et al. (2011, 2014), there were LTR scores for 43 taxa out of the 92 recorded in the 16 Greek lakes. Most of the taxa not included were helophytes, which in some cases were the only representatives of macrophytic vegetation in eutrophic and degraded lakes. These taxa provide reliable information on ecosystem ecological conditions and can support assessment of the ecological status of lakes under eutrophication pressure (Alahuhta et al. 2012; Kolada 2014, 2016). Moreover, the inclusion of helophytes is recommended since the assessment of eutrophication seems to be more reliable when more scored taxa are considered (Kolada 2014; Kolada et al. 2011). So, following the method used by Kolada et al. (2011, 2014), the missing LTRs were estimated from the regression equation between LTR values and the indicator values of Ellenberg for nutrients $\mathrm{N}$ (Ellenberg 1988; Ellenberg et al. 1991): LTR= $1.395 N-0.6276\left(R^{2}=0.64, n=98, p<0.0001\right)$. At the current state, LTR scores for macrophytic taxa, as calculated during the pan-European intercalibration exercise, were used due to lack of available data for the development of a Mediterranean or a Greek specific taxa list. The other two modifications were made to optimize the $\mathrm{ICM}_{\mathrm{LM}}$ metric. Cover-abundance values and metric calculations per transect are commonly used in calculations of trophic indices in other MS assessment methods (Hellsten et al. 2014; Pall et al. 2014; Portielje et al. 2014). For the calculation of the weighted average of LTR values per transect, the LTR value of each taxon was multiplied with its relative abundance within the transect. The latter was calculated after transforming the ordinal values of DAFOR scale to percentage cover values on the basis of the following correspondence: dominant $=87.5 \%$, abundant $=50 \%$, frequent $=17.5 \%$, occasional $=5.5 \%$, and rare $=0.5 \%$, and raising the percentage cover values to the power 0.2 , to avoid a high weight of dominant taxa in the index. Finally, a TIHeLM value for each lake was calculated by averaging the TIHeLM values of the transects sampled in the lake.

\section{Maximum depth of colonization $\left(C_{\max }\right)$}

All 16 lakes in the current data set have mean depth above $3 \mathrm{~m}$, so $C_{\max }$ was chosen as the best available macrophytic abundance metric (Kolada 2014; Kolada 
et al. 2011, 2014). As Kolada et al. (2011, 2014) remarked, $C_{\max }$ is subject to annual variations, which should be taken into account to reduce the risk of misclassification of a lake. For that reason, the value that we used in the HeLM assessment method for each lake was the mean average of annual $C_{\max }$ values measured in the 3-year period.

\section{Establishment of type-specific reference conditions}

Establishment of reference conditions for BQEs is crucial to ecological assessment of surface water bodies, as their ecological status is determined by their degree of deviation from these conditions. Sites in reference conditions do not equate to water bodies in pristine state. They are defined as those expected in natural or nearnatural state, with no or minimal disturbance and with human pressure resulting in minor effects on biological elements (European Commission 2003b).

Reference conditions for HeLM assessment method were based on existing near-natural reference sites, with the application of appropriate pressure criteria (e.g., European Commission 2003b; Poikane et al. 2015):

- Total phosphorus concentration (TP) calculated as mean annual value,

- Chlorophyll $a$ concentration (CHLA) calculated as mean summer value (June-August),

- Secchi depth (SD) calculated as mean summer value (June-August),

- Artificial land use (ALU), composed of the sum of percent cover of all the categories of CLC belonging to class 1 (urban areas continuous and discontinuous, industrial and commercial zones, communication infrastructures and networks, mines, etc.) in the catchment area,

- Intensive agriculture (IA), composed of the sum of percent cover of CLC categories corresponding to a high potential impact from agricultural activities (arable and irrigated land, permanent and annual crops, vineyards, orchards, olive groves, complex cultivation patterns; CLC codes 2.1, 2.2, 2.41, 2.4.2) in the catchment area,

- Natural and semi-natural land use (NASN), composed of the sum of percent cover of forest and natural areas, wetlands, and water bodies (CLC codes 3.1.1, 3.1.2, 3.1.3, 3.2, 3.3, 4, and 5) in the catchment area,
- Population density (PD), calculated as inhabitants per square kilometer $\left(\mathrm{h} / \mathrm{km}^{2}\right)$ in the catchment area.

Many of these pressure criteria may be correlated strongly to each other, but applying all of them simultaneously is expected to give a better filtering of lowimpacted and thus potential reference sites. For each one of them, a threshold value has been determined (Table 2), for accepting or rejecting a site as a potential reference one, similar to the ones set in Mediterranean MS (e.g., Pahissa et al. 2015). If a site fails even in one of these pressure criteria, then it cannot be considered as a reference site.

After the initial screening on the basis of pressure criteria, an extra step of filtering was applied, in order to disqualify sites that deviate significantly (outlier values) from those expected under reference conditions. Such deviations could be found for sites with no apparent anthropogenic pressures, but with restricted macrophyte development due to extreme natural landscape parameters (e.g., substrate restrictions, extreme inclination). Sites that qualified for both stages of the screening process were considered to represent reference conditions and were used in the ecological status class boundary setting procedure.

\section{Ecological status class boundary setting procedure}

Reference values and ecological status class boundaries for TIHeLM and $C_{\max }$ were calculated as recommended by REFCOND (European Commission 2003b). For TIHeLM, common class boundaries for both national lake types (GR-DNL and GR-SNL) were established, since taxonomic composition was not affected by their difference in maximum depth (there were no deep lake specific taxa and no more depth zone divisions after $8 \mathrm{~m}$ of depth). Different class boundaries were calculated for $C_{\text {max }}$, since the potential maximum colonization depth in GR-SNLs is limited by their maximum depth, in contrast to GR-DNLs which do not have this limitation.

Reference values for both TIHeLM and $C_{\max }$ metrics were determined as the median values in the selected reference sites. Subsequently, each lake's metric values were transformed to ecological quality ratios (EQRs) by dividing them by those reference values. In order to determine a high/good $(\mathrm{H} / \mathrm{G})$ class boundary for each metric, the 90th percentile (P90) of the distribution of its values in the selected reference sites was used (European Commission 2003b). To determine good/ 
Table 2 Pressure criteria and their threshold limits established for screening potential reference sites, following the results from Pahissa et al. (2015)

\begin{tabular}{|c|c|c|c|c|c|c|c|}
\hline National lake type & $\mathrm{TP}(\mu \mathrm{g} / \mathrm{L})$ & CHLA $(\mu \mathrm{g} / \mathrm{L})$ & $\mathrm{SD}(\mathrm{m})$ & $\operatorname{ALU}(\%)$ & IA $(\%)$ & NASN (\%) & $\mathrm{PD}\left(\mathrm{h} / \mathrm{km}^{2}\right)$ \\
\hline Deep natural lakes (GR-DNL) & $<12$ & $<2$ & $>6$ & $<4$ & $<25$ & $>70$ & $<30$ \\
\hline Shallow natural lakes (GR-SNL) & $<15$ & $<5$ & $>2$ & $<4$ & $<25$ & $>70$ & $<30$ \\
\hline
\end{tabular}

moderate $(\mathrm{G} / \mathrm{M})$ class boundaries, we followed the resulting TP range adopted for the Mediterranean Assessment System for Phytoplankton NMASRP (de Hoyos et al. 2014; Pahissa et al. 2015). We also assessed this range's relevance with our data by checking the changes in aquatic plant life-forms predominance and composition/abundance metrics along the eutrophication gradient. This TP range was found to correspond to the transition point from submerged-dominated to helophyte-dominated macrophytic communities (Online Resource, Supplement 2) and to the space before the metrics cross-over point (which is associated with moderate ecological status sites) in a paired metric analysis between TIHeLM, $C_{\max }$, and TP (Online Resource, Supplement 3 ). Thus, G/M class boundaries were determined at 75th percentile (P75) of the distribution of each metric's values, in sites that belong to the $20-50-\mu \mathrm{g} / \mathrm{L}$ TP group (de Hoyos et al. 2014). For the remaining class boundaries, the EQRs ranging from below the G/M class boundary to their minimum values were equally divided to form the moderate/poor (M/P) class boundary and poor/bad (P/B) class boundary (European Commission 2003b).

\section{Final calculation of EQR for each lake and assessment of its ecological status}

For the combination of the two metrics (TIHeLM and $\left.C_{\max }\right)$ in a final value for each lake, a normalization procedure of each lake's EQR values was applied following piecewise linear interpolation (Hazewinkel 2002) between each status class' upper and lower boundary value. This implied the conversion of each metric's EQR to a normalized scale with equal class widths and standardized class boundaries, where the high-good $(\mathrm{H} / \mathrm{G})$, good-moderate $(\mathrm{G} / \mathrm{M})$, moderatepoor $(\mathrm{M} / \mathrm{P})$, and poor-bad $(\mathrm{P} / \mathrm{B})$ boundaries were at $0.8,0.6,0.4$, and 0.2 , respectively.

The final lake assessment was determined using the principle of equal weight for taxonomic composition and abundance metrics. Thus, following the calculation of EQRs for both metrics and their normalization procedure for each lake, a final HeLM score and its subsequent ecological status class were calculated by their average.

Statistical assessment of method's performance

In order to evaluate the performance of the HeLM assessment method addressing eutrophication and general degradation pressures, the pressure-response relationships were investigated. The pressure indicators used for the evaluation of the metrics were TP, CHLA, and SD. By means of linear regression analysis and multivariate regression analysis (Legendre and Legendre 1998), the relationships between the three pressure indicators and the two metrics of the method separately as well as the final values of the HeLM method were determined.

To improve data distribution, TIHeLM metric values were log-transformed, while $C_{\max }$ metric values were square-root-transformed. The transformation of HeLM final values did not improve the distribution; thus, the values remained untransformed. Pressure indicator values were all log-transformed. For linear relationships, a linear regression model was applied using IBM SPSS Statistics v.23 (IBM 2014) software, and the resulting coefficient of determination $\left(R^{2}\right)$, Pearson's correlation coefficient $(R)$, and $p$ value $(p)$ of the model were assessed. As proposed by Kolada et al. (2011), the values of the coefficients $R^{2}>0.30$ and $R>0.55$, for statistically significant models $(p<0.05)$, were assumed as sufficient to accept a metric as a well-performing one. For the relationship between HeLM and all three pressure indicators, a multivariate regression model was applied and the same coefficients were assessed using the same software.

Finally, relative abundance values of different lifeforms of the macrophytic vegetation (elodeids, helophytes, charids, ceratophyllids, nymphaeids, and lemnids) were calculated for each lake. These values were plotted against the calculated metric values for 
each lake and polynomial adjustments were applied using IBM SPSS Statistics v.23 software (IBM 2014), in order to quantify the responses of different groups of aquatic macrophytes along the eutrophication gradient.

\section{Results}

Development of the HeLM assessment method

In total, 92 macrophyte taxa were recorded in 16 Greek lakes. The lists of these taxa along with their LTR values for the calculation of TIHeLM are given in Online Resource, Supplement 4.

Based on the environmental data used as pressure indicators, three lakes were selected as potential reference ones: Kourna and Feneos (GR-DNL type) and Paralimni (GRSNL type) (Table 3). The difference in the distribution of the pressure criteria values between non-reference and reference lakes is shown in Online Resource, Supplement 5. For these three lakes, 41 out of the 43 sampled transects were qualified as reference on the basis of the macrophytic vegetation and they were selected to represent reference conditions. Following the setting of reference conditions, type-specific ecological status class boundaries were calculated for each metric (Table 4).

\section{HeLM method application}

The results of the calculations of TIHeLM and $C_{\max }$ for the 16 Greek lakes (raw values and normalized ecological quality ratios), the final HeLM values, and the consequent ecological status class for each lake are given in Table 5. Twelve out of the 16 lakes were classified at high and good ecological status. The remaining four were positioned in the lower classes. In six lakes (Kourna, Feneos, Trichonida,
Paralimni, Lysimachia, and Zazari), both metrics independently resulted in classifying them in the same ecological status class. For the other 10, the two metrics gave results that differ up to two classes of ecological status. TIHeLM values exhibited a similar variance among the transects within each lake (Online Resource, Supplement 6). An obvious exception was Lysimachia lake (LYS), in which half of its transect showed a high level of degradation, whereas the other half did not.

\section{Evaluation of HeLM method's performance}

All linear regression models between the TIHeLM, $C_{\max }$, and HeLM values and the three pressure indicators were found significant at the 0.01 level, with coefficient of determination $\left(R^{2}\right)$ higher than 0.3 (the lower value was 0.454 ) and Pearson's correlation coefficient $(R)$ higher than 0.5 (the lower value was 0.674 ) (Table 6). Specifically, the TIHeLM metric showed a relatively high positive correlation with TP and CHLA, and an equal negative correlation with SD (Fig. 2 and Table 6). On the other hand, $C_{\max }$ metric showed a high negative correlation with TP and CHLA and an equal positive one with SD (Fig. 2 and Table 6). More importantly, final HeLM values showed a high negative correlation with TP and CHLA, and a high positive one with SD (Fig. 3 and Table 6). The multivariate regression analysis was also significant at the 0.01 level and with high coefficient of determination $\left(R^{2}\right)$ and Pearson's correlation coefficient $(R)$ (Table 6). Best linear fits, limits of $95 \%$ confidence, and prediction limits are shown in Figs. 2 and 3.

Figure 4 represents the changes in relative abundance of different life-forms of macrophytes over the range of values of both taxonomic composition metric (TIHeLM) and abundance metric $\left(C_{\max }\right)$, as well as the final HeLM assessment method values. In all three

Table 3 The lakes selected to represent reference conditions, after the pressure screening process, with their calculated values for the selected indicators of eutrophication and general degradation pressure

\begin{tabular}{lllllllll}
\hline Lake & Type & TP $(\mu \mathrm{g} / \mathrm{L})$ & CHLA $(\mu \mathrm{g} / \mathrm{L})$ & SD $(\mathrm{m})$ & ALU $(\%)$ & IA $(\%)$ & NASN $(\%)$ & PD $\left(\mathrm{h} / \mathrm{km}^{2}\right)$ \\
\hline Kourna & GR-DNL & $<10$ & 1.27 & 7.5 & 0.00 & 2.70 & 97.30 & 6.68 \\
Feneos & GR-DNL & 10.27 & 0.47 & 9.9 & 0.00 & 0.00 & 95.47 & 0.00 \\
Paralimni & GR-SNL & 13.63 & 3.78 & 2.5 & 0.16 & 22.24 & 77.59 & 9.57 \\
\hline
\end{tabular}

For the pressure indicator abbreviations, see Materials and methods / Development of the HeLM assessment method / Establishment of typespecific reference conditions Section

$G R-D N L$ Greek deep natural lakes, GR-SNL Greek shallow natural lakes 
Table 4 The type-specific ecological status class boundaries (ecological quality ratio and raw values) as calculated for each metric of the HeLM assessment method

\begin{tabular}{|c|c|c|c|c|c|c|}
\hline Metric & \multicolumn{2}{|l|}{ TIHeLM } & \multicolumn{2}{|l|}{$C_{\max }(\mathrm{m})$} & \multicolumn{2}{|l|}{$C_{\max }(\mathrm{m})$} \\
\hline National lake types & \multicolumn{2}{|c|}{ GR-DNL and GR-SNL } & \multicolumn{2}{|l|}{ GR-DNL } & \multicolumn{2}{|l|}{ GR-SNL } \\
\hline Class & EQR & Value & EQR & Value & EQR & Value \\
\hline Reference & 1 & 7.14 & 1 & 12.2 & 1 & 6.1 \\
\hline High & $>0.94$ & $<7.60$ & $>0.89$ & $>10.86$ & $>0.69$ & $>4.21$ \\
\hline Good & $0.94-0.90$ & $7.60-7.93$ & $0.89-0.36$ & $10.86-4.39$ & $0.69-0.58$ & $4.21-3.54$ \\
\hline Moderate & $<0.90-0.82$ & $>7.93-8.71$ & $<0.36-0.24$ & $<4.39-2.93$ & $<0.58-0.39$ & $<3.54-2.38$ \\
\hline Poor & $<0.82-0.75$ & $>8.71-9.52$ & $<0.24-0.12$ & $<2.93-1.46$ & $<0.39-0.19$ & $<2.38-1.16$ \\
\hline $\mathrm{Bad}$ & $<0.75$ & $>9.52$ & $<0.12-0$ & $<1.46-0$ & $<0.19-0$ & $<1.16-0$ \\
\hline
\end{tabular}

GR-DNL Greek deep natural lakes, GR-SNL Greek shallow natural lakes

cases, a clear trend was observed of elodeid-dominated macrophytic communities at high ecological status lakes being replaced by helophyte-dominated macrophytic communities at lakes of lower ecological status classes. Charids were also quite commonly found in lakes at higher classes, and they were absent in lakes at lower classes. On the other hand, lemnids and nymphaeids showed a slight increasing trend towards lakes at lower classes of ecological status.

\section{Discussion}

Development of the HeLM assessment method

Our results show that HeLM assessment method is a fully WFD-compliant assessment method, able to classify the Greek lakes according to their ecological status. Currently, 17 MS have developed, intercalibrated, and harmonized their methods for assessing the ecological

Table 5 Calculated values for metrics TIHeLM and $C_{\max }$ of the HeLM assessment method (raw values and normalized ecological quality ratios (nEQRs)) and final assessment of the ecological status for each one of the 16 lakes of the Greek National Water Monitoring Network

\begin{tabular}{|c|c|c|c|c|c|c|c|}
\hline Lake & Type & TIHeLM & nEQR TIHeLM & $C_{\max }(\mathrm{m})$ & $\mathrm{nEQR} C_{\max }$ & HeLM & Ecological status \\
\hline Kourna & GR-DNL & 7.163 & 0.989 & 13.20 & 1.000 & 0.995 & High \\
\hline Feneos & GR-DNL & 7.322 & 0.917 & 12.80 & 1.000 & 0.959 & High \\
\hline Megali Prespa & GR-DNL & 7.483 & 0.847 & 7.00 & 0.681 & 0.764 & Good \\
\hline Trichonida & GR-DNL & 7.694 & 0.740 & 10.00 & 0.773 & 0.757 & Good \\
\hline Amvrakia & GR-DNL & 7.497 & 0.841 & 6.60 & 0.668 & 0.755 & Good \\
\hline Vegoritida & GR-DNL & 7.579 & 0.807 & 7.67 & 0.701 & 0.754 & Good \\
\hline Volvi & GR-DNL & 7.444 & 0.864 & 3.87 & 0.528 & 0.696 & Good \\
\hline Yliki & GR-DNL & 7.439 & 0.866 & 3.80 & 0.519 & 0.693 & Good \\
\hline Paralimni & GR-SNL & 7.141 & 1.000 & 6.80 & 1.000 & 1.000 & High \\
\hline Doirani & GR-SNL & 7.783 & 0.687 & 4.67 & 0.848 & 0.768 & Good \\
\hline Mikri Prespa & GR-SNL & 8.389 & 0.478 & 5.60 & 0.947 & 0.712 & Good \\
\hline Kastoria & GR-SNL & 8.119 & 0.548 & 4.40 & 0.820 & 0.684 & Good \\
\hline Lysimachia & GR-SNL & 7.958 & 0.593 & 3.40 & 0.576 & 0.585 & Moderate \\
\hline Ozeros & GR-SNL & 8.788 & 0.379 & 3.10 & 0.524 & 0.452 & Moderate \\
\hline Zazari & GR-SNL & 8.737 & 0.392 & 1.40 & 0.240 & 0.316 & Poor \\
\hline Pamvotida & GR-SNL & 9.068 & 0.307 & 0.53 & 0.092 & 0.199 & $\mathrm{Bad}$ \\
\hline
\end{tabular}

GR-DNL Greek deep natural lakes, GR-SNL Greek shallow natural lakes 
Table 6 Overview of the relationships between HeLM metrics (TIHeLM and $C_{\max }$ ) and HeLM final values and pressure indicator values (total phosphorus concentration, TP; chlorophyll $a$

\begin{tabular}{|c|c|c|c|c|c|}
\hline Relationship & $n$ & $R^{2}$ & $R$ & $p$ & Regression equation \\
\hline TIHeLM-TP & 16 & 0.494 & 0.703 & 0.002 & $\log T I H e L M=0.049 \times \log T P+0.821$ \\
\hline TIHeLM-CHLA & 16 & 0.454 & 0.674 & 0.004 & $\log T I H e L M=0.031 \times \log C H L A+0.865$ \\
\hline TIHeLM-SD & 16 & 0.475 & -0.689 & 0.003 & $\log T I H e L M=0.912-0.051 \times \log S D$ \\
\hline$C_{\max }-\mathrm{TP}$ & 16 & 0.686 & -0.828 & $<0.001$ & $\sqrt{C \max }=4.379-1.383 \times \log T P$ \\
\hline$C_{\max }-\mathrm{CHLA}$ & 16 & 0.808 & -0.899 & $<0.001$ & $\sqrt{C m a x}=3.247-0.994 \times \log C H L A$ \\
\hline$C_{\max }-\mathrm{SD}$ & 16 & 0.751 & 0.867 & $<0.001$ & $\sqrt{C \max }=1.528 \times \log S D+1.764$ \\
\hline HeLM-TP & 16 & 0.682 & -0.826 & $<0.001$ & $H e L M=1.276-0.39 \times \log T P$ \\
\hline HeLM-CHLA & 16 & 0.655 & -0.809 & $<0.001$ & $H e L M=0.931-0.253 \times \log C H L A$ \\
\hline HeLM-SD & 16 & 0.580 & 0.762 & $<0.001$ & $H e L M=0.38 \times \log S D+0.556$ \\
\hline HeLM-TP, CHLA, and SD & 16 & 0.694 & -0.833 & 0.002 & $H e L M=1.256-0.29 \times \log T P-0.112 \times \log C H L A-0.068 \times \log S D$ \\
\hline
\end{tabular}

concentration, CHLA; and Secchi depth, SD), after linear regression and multivariate regression analysis

The coefficient of determination $\left(R^{2}\right)$, Pearson's correlation coefficient $(R)$, and the $p$ value of significance are given for each regression

Fig. 2 Linear relationships between the metrics TIHeLM (ac) and $C_{\max }(\mathbf{e}-\mathbf{g})$ and the pressure indicators total phosphorus (TP), chlorophyll $a$ (CHLA), and Secchi depth (SD). Best linear fits, limits of $95 \%$ confidence, and prediction limits are shown. Best linear fits' equations and coefficients can be seen at Table 6 a

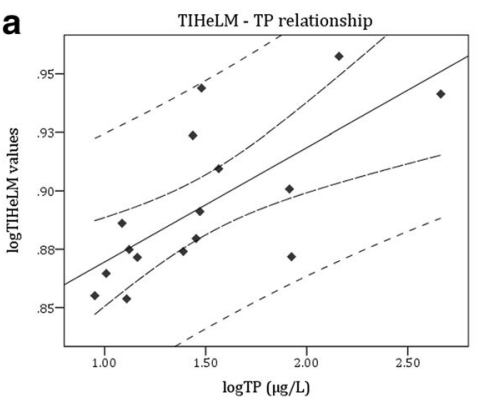

b

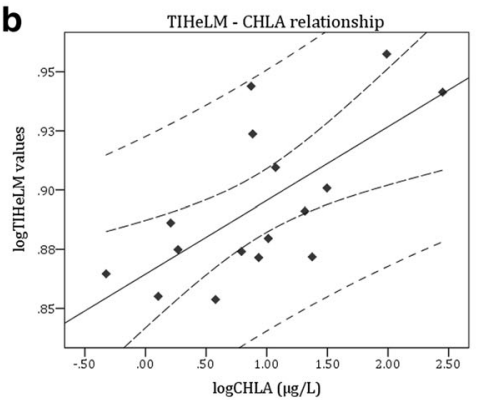

C

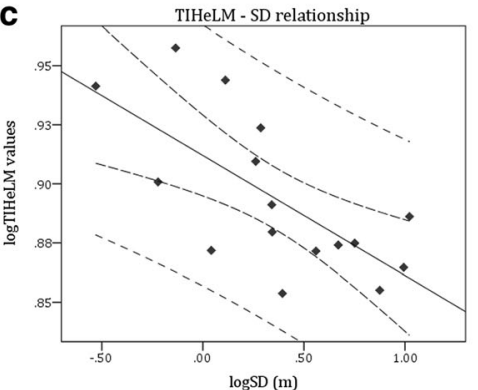

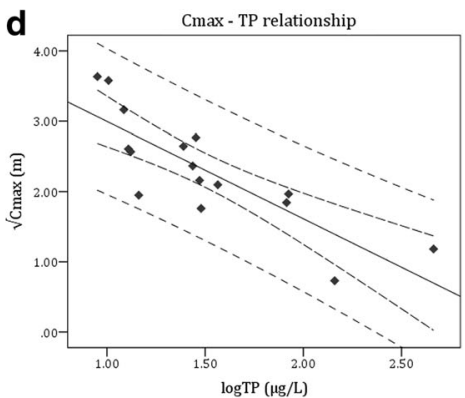

e

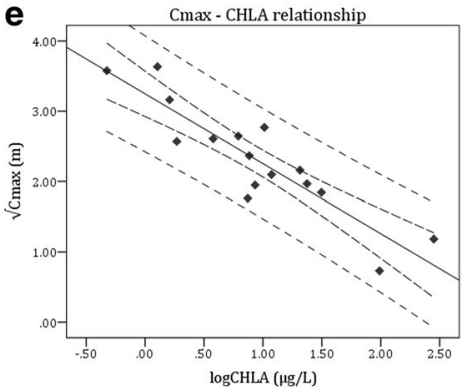

f

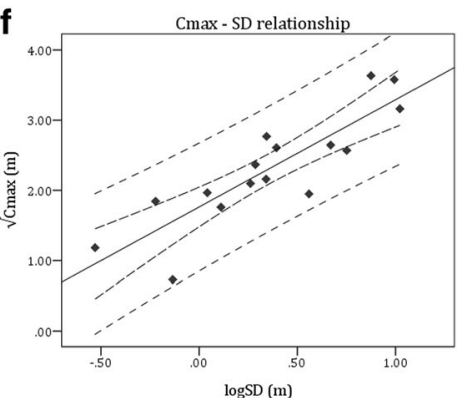



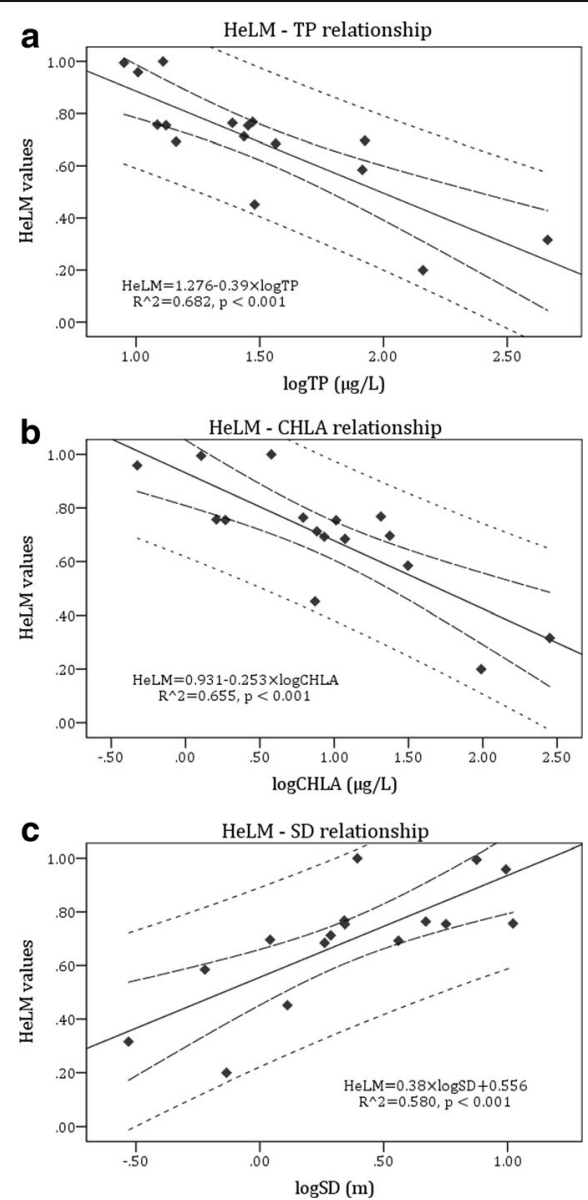

Fig. 3 Linear relationships between final HeLM values and the pressure indicators total phosphorus (TP) (a), chlorophyll $a$ (CHLA) (b), and Secchi depth (SD) (c). Best linear fits, limits of $95 \%$ confidence, and prediction limits are shown. Best linear fits' equations and coefficients can be seen at Table 6

status of lakes based on aquatic macrophytes (European Commission 2013; Poikane et al. 2011). All these MS, without exception, belong to the Central and Northern European regions, whereas there is still not a fully harmonized method in Mediterranean region (Poikane et al. 2011, 2015). In these methods, MS follow three approaches with regard to the assessment of macrophyte taxonomic composition. The first is based on the relative abundance of sensitive and/or tolerant taxa [e.g., Dutch method (Coops et al. 2007), Norwegian method (Mjelde 2007), German method (Schaumburg et al. 2004)], the second on diversity indices [e.g., Polish method (Portielje et al. 2014), British method (Willby et al. 2009)], and the third approach on trophic scores of taxa [e.g., Swedish method (Ecke 2007), Austrian method (Pall and Moser 2009)]. In regard to abundance,
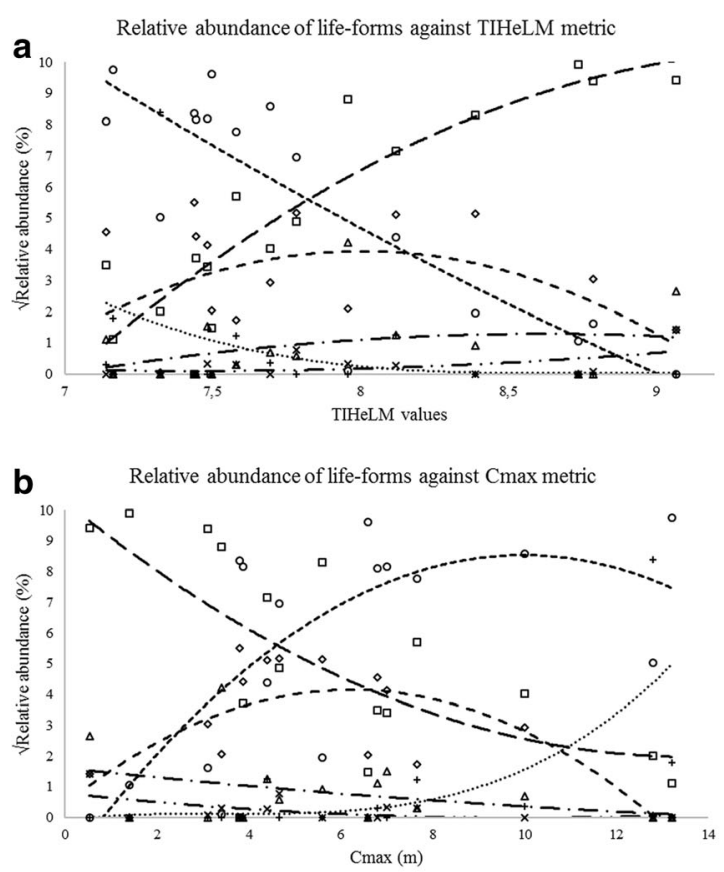

C

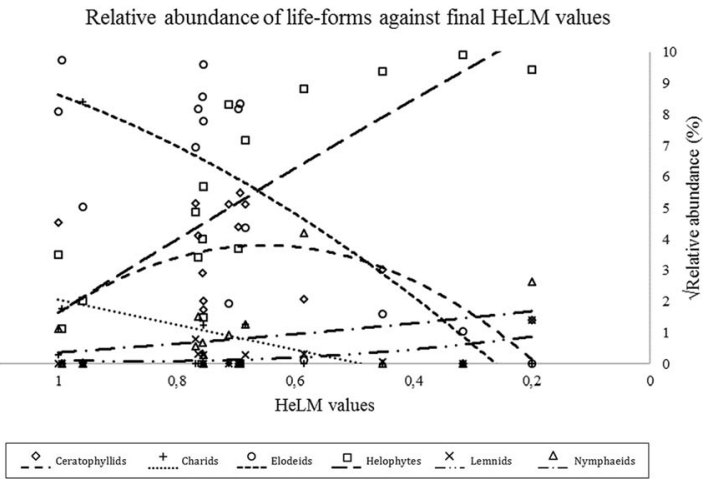

Fig. 4 Scatterplots between TIHeLM (a), $C_{\max }$ (b), and final HeLM values (c) and the calculated relative abundance (squareroot-transformed) of different life-forms of macrophytes in the studied lakes. The lines represent polynomial adjustments

maximum colonization depth $\left(C_{\max }\right)$ is commonly used in the assessment methods of many other MS [e.g., Irish method (Free et al. 2006), Austrian method (Pall and Moser 2009), German method (Schaumburg et al. 2004), Danish method (Sondergaard et al. 2010)]. Based on the results of our tests that applied the rationale of Dudley et al. (2011) and Kolada et al. (2011, 2014), $C_{\max }$ and a trophic score index were chosen to become the constituent metrics of HeLM assessment method.

Another important issue we had to address during the development of a water ecological status assessment method was the establishment of reference conditions and ecological status class boundaries. In the HeLM 
method, potential reference sites were selected on the basis of pressure indicators and ecological criteria which present the potential anthropogenic effect in the catchment area of the lakes. These criteria were also recommended by REFCOND (European Commission 2003b) and were among the ones that are commonly used in other published assessment methods (Pahissa et al. 2015; Pall et al. 2016; Poikane et al. 2015; Portielje et al. 2014, etc.). Reference conditions for European lakes have been mostly developed on the basis of phytoplankton, with accepted lakes having annual TP concentrations up to $35 \mu \mathrm{g} / \mathrm{L}$ and annual CHLA concentrations up to $5 \mu \mathrm{g} / \mathrm{L}$ (Cardoso et al. 2007; Carvalho et al. 2008; McElarney and Rippey 2009; Toth et al. 2008). Thus, the thresholds set for reference criteria in HeLM method are consistent with those found in assessment methods of other MS (Hellsten et al. 2014; Portielje et al. 2014). Ecological status class boundaries were set following the recommendations of REFCOND (European Commission 2003b) and the work done in Mediterranean region (Pahissa et al. 2015). The resulted values are also comparable with the boundary values set in other MS (Hellsten et al. 2014; Portielje et al. 2014). However, for their final refinement, more data concerning changes in species compositions in Mediterranean lakes may be required.

Application and evaluation of the HeLM method's performance

TIHeLM and $C_{\max }$ independently do not always result in the same ecological status. There were cases that $C_{\max }$ classified the lake to a lower class than TIHeLM and vice versa. This can be attributed to the different time of response of the two metrics to changes in water quality. Taxonomic composition of macrophytes has been found to respond relatively slow to changes of trophic conditions, requiring some years to adapt to the new conditions within a lake (Jeppesen et al. 2005; Mehner et al. 2008; Melzer 1999; Robertson et al. 2000). On the other hand, $C_{\max }$ seems to adapt much faster to changes of trophic conditions (Asplund and Cook 1997; Mehner et al. 2008; Robertson et al. 2000; van den Berg et al. 1999). For this reason, it is important for an assessment method to cover different aspects of macrophytic vegetation, with the inclusion of short-time as well as longtime reacting components to eutrophication and reoligotrophication processes (Pall and Moser 2009; Portielje et al. 2014; Schaumburg et al. 2004).
Furthermore, calculation of the spatial variability of TIHeLM among transects within each lake can be a valuable tool for the identification of point sources of water pollution and the prevalence of different levels of ecological status in different sub-bodies of a lake (Brazner et al. 2007; Niemi et al. 2004). For example, in our data set, around half of Lysimachia lake showed a high level of degradation due to eutrophication and general degradation pressures, whereas the other half that receives water from the nearby lake Trichonida (Avramidis et al. 2013) did not.

The performance of the HeLM assessment method was tested by exploring the relationships of its constituent metrics with the most common eutrophication pressure indicators. The data set that was used for the above-mentioned test covered the full nutrient-pressure gradient that can be found in Greek natural lakes, so as to evaluate the reliability of the method to classify water bodies in all different classes of ecological status. The majority of the sites in the data set used were within the confidence limits (95\%) of the assessment model, while all of them were within its prediction limits for all three pressure indicators. The final HeLM values were found to describe eutrophication pressures strongly and with high significance. For example, the coefficient of determination $\left(R^{2}\right)$ in the correlation with TP was found at $R^{2}=0.682$. This value is among the highest values found in assessment systems of other MS (e.g., Finland $\mathrm{TP}, R^{2}=0.29$; Ireland TP, $R^{2}=0.56$; Norway TP, $R^{2}=$ 0.65 ; United Kingdom TP, $R^{2}=0.48$; Germany TP, $R^{2}=0.50$; France TP, $R^{2}=0.33$; Austria TP, $R^{2}=0.27$ ) (Hellsten et al. 2014; Pall et al. 2014; Portielje et al. 2014). Furthermore, all values of determination coefficient $\left(R^{2}\right)$ and Pearson's correlation coefficient $(R)$, for all correlations between HeLM's metrics and final values and pressure indicator values, over-exceeded the thresholds of $R^{2}>0.30$ and $R>0.55$ proposed for well-performing metrics by Kolada et al. (2011). All the above are indicative of the effective performance of the HeLM assessment method in addressing eutrophication and general degradation pressures in Greek natural lakes.

Individual metric and final HeLM values were also found to discriminate quite well the lakes where elodeids and charids are dominating the macrophytic vegetation from the lakes where only helophytes, lemnids, and nymphaeids are present and thus the shift from a submerged macrophytic vegetation to an emergent one (Kolada 2014). This shift has been found to be 
strongly connected with a change from a transparent state of water to a turbid one, thus representing a water deterioration gradient (Hilt et al. 2010; Klosowskii et al. 2006; Kohler et al. 2010; Kolada 2014; Spoljar et al. 2017). Specifically, a great number of charophytes and elodeids are considered as indicative of high and good ecological status sites (Hellsten et al. 2014; Pall et al. 2014; Portielje et al. 2014), while for less than good status communities, the above-mentioned taxa are being replaced by more tolerant taxa, such as nymphaeids, lemnids, and helophytes (Kolada 2014; Pall et al. 2014; Penning et al. 2008a, b; Portielje et al. 2014; Toth et al. 2008).

\section{Limitations and future needs}

The taxonomic composition metric TIHeLM used in the HeLM assessment method is a trophic score metric, calculated on the basis of species trophic scores (LTR). Since there is neither a current trophic scoring system for macrophytes in Greek lakes nor the amount of data necessary for the development of one, the calculation of the TIHeLM metric uses the scoring system resulted from the European intercalibration exercise (Hellsten et al. 2014; Kolada et al. 2011, 2014). Furthermore, new LTR values have been calculated by applying a regression (Kolada et al. 2011) for about half of the taxa recorded in our data set, as no LTR values existed for them. The continuous operation of Monitoring Networks by Mediterranean MS will provide more data considering TP optima for macrophytes in the Mediterranean region in the future; thus, the LTR values of taxa may be revised to represent more accurately their response to the trophic status of lakes.

An additional issue to be treated is that the development of the HeLM assessment method was based on a data set representing 16 lakes and a 3-year sampling period. Future sampling campaigns in the context of the monitoring network will provide additional data. As more data become available, the method needs to be checked and revised accordingly in subjects such as analysis of the uncertainty, temporal stability of metric values within reference sites, analysis of importance of the inclusion or not of specific groups of taxa in the metrics calculation, and readjustment of boundary locations according to changes in species composition.

Finally, an important issue for the future is the harmonization of the methods used in the Mediterranean region. Following the development efforts for the
French macrophyte assessment method for lakes, IBML (Bertrin et al. 2016), Italian macrophyte method VLMMI (Azella 2016), and the Spanish assessment method (CEDEX 2010a, b), all Mediterranean MS, should focus on the intercalibration of their adopted methods, in order to ensure that good ecological status represents the same level of ecological quality for all lakes in the Mediterranean region, consistent with WFD normative definitions (Poikane et al. 2011; Toth et al. 2008).

\section{Conclusions}

The WFD-compliant HeLM assessment method for macrophytes in Mediterranean lakes in Greece was developed on the basis of two metrics concerning the taxonomic composition and abundance of aquatic macrophytes. According to the so far collected data from the Greek National Water Monitoring Network, the developed method depicts in a satisfactory manner the response of aquatic macrophytes to eutrophication and general degradation pressures. It is also able to discriminate lakes with macrophytic vegetation dominated by different life-forms. In the light of new data and under the requirements among other MS in the Mediterranean region, future additions and improvements in this assessment method may be required.

Acknowledgements The present study was executed in the frame of the Greek National Water Monitoring Network, according to the JMD 140384/2011, implemented by The Goulandris Natural History Museum, Greek Biotope/Wetland Centre (EKBY). The study was co-financed by the European Union Cohesion Fund (Partnership Agreement 2014-2020, MIS 5001204. The network is supervised by the Directorate for the Protection and Management of Water Resources of the Special Secretariat for Waters of the Ministry of Environment and Energy. The data used in this report come from Acts MIS 371010, 371138, 371140, 371144, and 371145 of the Operational Program "Environment and Sustainable Development" financed by the European Regional Development Fund. Special thanks must be given to G. Poulis for his contribution to aquatic macrophyte samplings and identification and to E. Tsakiri for the identification of bryophytes. EKBY's personnel conducted monitoring samplings and analysis of pressure data.

Open Access This article is distributed under the terms of the Creative Commons Attribution 4.0 International License (http:// creativecommons.org/licenses/by/4.0/), which permits unrestricted use, distribution, and reproduction in any medium, provided you give appropriate credit to the original author(s) and the source, provide a link to the Creative Commons license, and indicate if changes were made. 


\section{References}

Alahuhta, J., Kanninen, A., \& Vuori, K. M. (2012). Response of macrophyte communities and status metrics to natural gradients and land use in boreal lakes. Aquatic Botany, 103, 106114.

Alvarez Cobelas, M., Rojo, C., \& Angeler, D. G. (2005). Mediterranean limnology: current status, gaps and the future. Journal of Limnology, 64, 13-29.

Asplund, T. R., \& Cook, C. M. (1997). Effects of motor boats on submerged aquatic macrophytes. Lake and Reservoir Manage, 13, 1-12.

Avramidis, P., Samiotis, A., Kalimani, E., Papoulis, D., Lampropoulou, P., \& Bekiari, V. (2013). Sediment characteristics and water physicochemical parameters of the Lysimachia Lake, Western Greece. Environment Earth Science, 70, 383-392.

Azella, M.M. (2016). Report of the Italian macrophyte method for Mediterranean lakes: VL-MMI. https:/circabc.europa. eu/faces/jsp/extension/wai/navigation/ container.jsp. Accessed 05 Sept 2017.

Beklioglu, M., Romo, S., Kagalou, I., Quintana, X., \& Bé cares, E. (2007). State of the art in the functioning of shallow Mediterranean lakes: workshop conclusions. Hydrobiologia, 584, 317-326.

Bertrin, V., Boutry, S., Reyjol, Y., \& Argillier, C. (2016). French macrophyte assessment method for lakes, IBML (Indice Biologique Macrophytique lac): Report for Mediterranean Lakes intercalibration exercise. https://circabc.europa. eu/faces/ jsp/extension/wai/navigation/container.jsp. Accessed 05 Sept 2017.

Birk S., 2010. Database on assessment methods for lakes, rivers, coastal and transitional waters in Europe. Wiser deliverable D2.2-1. http://www.wiser.eu/results/ deliverables/. Accessed 03 Sept 2017.

Birk, S., Bonne, W., Borja, A., Brucet, S., Courrat, A., Poikane, S., Solimini, A., van de Bund, W., Zampoukas, N., \& Hering, D. (2012). Three hundred ways to assess Europe's surface waters: an almost complete overview of biological methods to implement the water framework directive. Ecological Indicators, 18, 31-41.

Blindow, I., Hargeby, A., Meyercordt, J., \& Schubert, H. (2006). Primary production in two shallow lakes with contrasting plant form dominance: a paradox of enrichment? Limnology and Oceanography, 51, 2711-2721.

Brazner, J. C., Danz, N. P., Trebitz, A. S., Niemi, G. J., Regal, R. R., Hollenhorst, T., Host, G. E., Reavie, E. D., Brown, T. N., Hanowski, J. A. M., Johnston, C. A., Johnson, L. B., Howe, R. W., \& Ciborowski, J. J. H. (2007). Responsiveness of Great Lakes wetland indicators to human disturbances at multiple spatial scales: a multi-assemblage assessment. Journal of Great Lakes Research, 33, 42-66.

Cardoso, A. C., Solimimi, A., Premazzi, G., Carvalho, L., Lyche, A., \& Rekolainen, S. (2007). Phosphorus reference concentrations in European lakes. Hydrobiologia, 584, 3-12.

Carvalho, L., Solimini, A., Phillips, G., van Den Berg, M., Pietilainen, O. P., Solheim, L. A., et al. (2008). Chlorophyll reference conditions for European lake types used for intercalibration of ecological status. Aquatic Ecology, 42, 203-211.

CEDEX. (2010a). Selección de métricas para la evaluación del estado ecológico de las masas de agua de la categoría "lagos" basadas en el elemento de calidad "composición y abundancia de otra flora acuática" en aplicación de la Directiva Marco del Agua. Clave CEDEX: 44-407-1-002.

CEDEX. (2010b). Establecimiento de condiciones de referencia y valores frontera entre clases de estado ecológico en masas de agua de la categoría lago para los elementos de calidad "composición, abundancia y biomasa de fitoplancton" y "composición y abundancia de otro tipo de flora acuática", en aplicación de la Directiva Marco del Agua. Clave CEDEX: 44-407- 1-002.

Coops, H., Kerkum, F. C. M., van den Berg, M. S., \& van Splunder, I. (2007). Submerged macrophytes vegetation and the European water framework directive: assessment of status and trends in shallow, alkaline lakes in the Netherlands. Hydrobiologia, 584, 395-402.

Copernicus Service - Pan-European Component: Corine Land Cover CLC (2012). Version 18.5.1. http://land.copernicus. eu/. Accessed 20 Aug 2017.

De Boer, W. (2007). Seagrass-sediment interactions, positive feedbacks and critical thresholds for occurrence: a review. Hydrobiologia, 591, 5-24.

van den Berg, M. S., Scheffer, M., van Nes, E., \& Coops, E. (1999). Dynamics and stability of Chara sp. and Potamogeton pectinatus in a shallow lake changing in eutrophication level. Hydrobiologia, 408, 335-342.

Dudley, B., Dunbar, M., Penning, E., Kolada, A., Hellsten, S., \& Kanninen, A. (2011). Report on uncertainty in macrophyte metrics. Wiser Deliverable D3.2-2. http://www.wiser. eu/results/deliverables/. Accessed 03 Sept 2017.

Ecke, F. (2007). Bedomningsgrunder for makrofyter i sjoar Bakgrundsrapport of Lulea University of Technology, department of chemical engineering and geosciences. Lulea, Sweden.

Ellenberg, H. (1988). Vegetation ecology of Central Europe (4th ed.). Cambridge: Cambridge University Press.

Ellenberg, H., Weber, H. E., Dull, R., Wirth, V., Werner, W., \& Paulissen, D. (1991). Zeigerwerte von Pflanzen in Mitteleuropa. Scripta Geobotanica, 18, 1-248.

Engelhardt, K. A. M., \& Ritchie, M. E. (2001). Effects of macrophyte species richness on wetland ecosystem functioning and services. Nature, 411, 687-689.

ETC/IC (2015). European Freshwater Ecosystem Assessment: cross-walk between the Water Framework Directive and Habitats Directive types, status and pressures, ETC/ICM Technical Report 2/2015, Magdeburg: European Topic Centre on inland, coastal and marine waters, 95 pp. plus Annexes.

European Commission (2000). Directive 2000/60/EC of the European Parliament and of the council of 23rd October 2000. Establishing a framework for community action in the field of water policy. Official journal of the European Communities, L327/1. European Commission, Brussels.

European Commission (2003a). Monitoring under the Water Framework Directive. Guidance document No. 7. Common implementation strategy for the Water Framework Directive (2000/60/EC). 
European Commission (2003b). Rivers and lakes - typology, reference conditions and classification systems. Guidance document No. 10. Common implementation strategy for the Water Framework Directive (2000/60/EC). Produced by Working Group 2.3 - REFCOND.

European Commission (2013). Commission decision of 20 September 2013 establishing, pursuant to directive 2000/60/ EC of the European Parliament and of the council, the values of the member state monitoring system classifications as a result of the intercalibration exercise. Official journal of the European Communities, L266/1. European Commission, Brussels.

Free, G., Little, R., Tierney, D., Donnelly, K., \& Caroni, R. (2006). A reference based typology and ecological assessment system for Irish Lakes. Preliminary Investigations. EPA, Wexford, Ireland.

Hazewinkel, M. (2002). Encyclopaedia of mathematics. Berlin: Springer-Verlag.

Hellenic Statistical Authority (2011). Population-housing census. http://www.statistics.gr/en/2011-census-pop-hous. Accessed 20 Aug 2017.

Hellsten, S., Willby, N., Ecke, F., Mjelde, M., Phillips, G., \& Tierney, D. (2014). Northern lake macrophyte ecological assessment methods. Water Framework Directive Intercalibration Technical Report. Joint Research Centre Technical Reports.

Hilt, S., Gross, E. M., Hupfer, M., Morscheid, H., Mahlmann, J., Melzer, A., et al. (2006). Restoration of submerged vegetation in shallow eutrophic lakes - a guideline and state of the art in Germany. Limnologica, 36, 155-171.

Hilt, S., Henschke, I., Rucker, J., \& Nixdorf, B. (2010). Can submerged macrophytes influence turbidity and trophic state in deep lakes? Suggestions from a case study. Journal of Environmental Quality, 39, 725-733.

Hoerling, M., Eischeid, J., Perlwitz, J., Quan, X., Zhang T., \& Pegion, P. (2012). On the increased frequency of Mediterranean drought. American Meteorological Society, Journal on Climate, 25, 2146-2161.

de Hoyos, C., Catalan, J., Dörflinger, G., Ferreira, J., Kemitzoglou, D., Laplace-Treyture, C., et al. (2014). Mediterranean Lake phytoplankton ecological assessment methods. Water Framework Directive Intercalibration Technical Report. Joint Research Centre Technical Reports.

I.S. EN 15460 (2007). Water quality - guidance standard for the surveying of macrophytes in lakes.

IBM Corp. (2014). IBM SPSS statistics for Windows, version 23.0. Armonk: IBM Corp.

Janauer, G.A. (2002). Guidance on the assessment of aquatic macrophytes in lakes under the conditions of the monitoring for the water framework directive/EU.

Jeffrey, S. W., \& Humphrey, G. F. (1975). New spectrophotometric equations for determining chlorophylls $a, b, c 1$ and $c 2$ in higher plants, algae and natural phytoplankton. Biochemie und Physiologie der Pflanzen, 167, 191-194.

Jensen, S. (1977). An objective method for sampling the macrophyte vegetation in lakes. Vegetatio, 33, 107-118.

Jeppesen, E., Sondergaard, M., Jensen, J. P., Havens, K. E., Anneville, O., Carvalho, L., et al. (2005). Lake response to reduced nutrient loading - an analysis of contemporary longterm data from 35 case studies. Freshwater Biology, 50, 1747-1771.
Klosowskii, S., Tomaszewicz, G. H., \& Tomaszewicz, H. (2006). The expansion and decline of charophyte communities in lakes within the Sejny Lake District (northeastern Poland) and changes in water chemistry. Limnologica, 36, 234-240.

Kohler, J., Hachoł, J., \& Hilt, S. (2010). Regulation of submersed macrophyte biomass in a temperate lowland river: interactions between shading by bank vegetation, epiphyton and water turbidity. Aquatic Botany, 92, 129-136.

Kolada, A. (2014). The effect of lake morphology on aquatic vegetation development and changes under the influence of eutrophication. Ecological Indicators, 38, 282-293.

Kolada, A. (2016). The use of helophytes in assessing eutrophication of temperate lowland lakes: added value? Aquatic Botany, 129, 44-54.

Kolada, A., Hellsten, S., Kanninen, A., Søndergaard, M., Dudley, B., Nõges, P., et al. (2009). Overview and comparison of macrophyte survey methods used in European countries and a proposal of harmonized common sampling protocol to be used for WISER uncertainty exercise including a relevant common species list. Wiser Deliverable D3.2-1. http://www. wiser.eu/results/deliverables/. Accessed 05 Sept 2017.

Kolada, A., Hellsten, S., Søndergaard, M., Mjelde, M., Dudley, B., Van Geest, G., et al. (2011). Report on the most suitable lake macrophyte based assessment methods for impacts of eutrophication and water level fluctuations. Wiser Deliverable D3.2-3. http://www.wiser.eu/results/deliverables/. Accessed 05 Sept 2017.

Kolada, A., Willby, N., Dudley, B., Noges, P., Sondergaard, M., Hellsten, S., et al. (2014). The applicability of macrophyte compositional metrics for assessing eutrophication in European lakes. Ecological Indicators, 45, 407-415.

Legendre, P., \& Legendre, L. F. G. (1998). Numerical ecology (2nd ed.). Amsterdam: Elsevier.

McElarney, Y. R., \& Rippey, B. (2009). A comparison of lake classifications based on aquatic macrophytes and physical and chemical water body descriptors. Hydrobiologia, 625, 195-206.

Mehner, T., Diekmann, M., Gonsiorczyk, T., Kasprzak, P., Koschel, R., Krienitz, L., Rumpf, M., Schulz, M., \& Wauer, G. (2008). Rapid recovery from eutrophication of a stratified lake by disruption of internal nutrient load. Ecosystems, 11, $1142-1156$.

Melzer, A. (1999). Aquatic macrophytes as tools for lake management. Hydrobiologia, 395, 181-190.

Mjelde, M. (2007). Macrophytes and eutrophication in lakes. BIOCLASS, NIVA-report, Oslo, Norway.

Niemi, G. J., Wardrop, D., Brooks, R., Anderson, S., Brady, V., Paerl, H., et al. (2004). Rationale for a new generation of ecological indicators for coastal waters. Environmental Health Perspectives, 112, 979-986.

Özen, A., Karapinar, B., Kucuk, I., Jeppesen, E., \& Beklioglu, M. (2010). Drought-induced changes in nutrient concentrations and retention in two shallow Mediterranean lakes subjected to different degrees of management. Hydrobiologia, 646, 61-72.

Pahissa, J., Catalan, J., Morabito, G., Dörflinger, G., Ferreira, J., Laplace-Treyture, C., Gîrbea, R., Marchetto, A., Polykarpou, P., \& de Hoyos, C. (2015). Benefits and limitations of an intercalibration of phytoplankton assessment methods based on the Mediterranean GIG reservoir experience. Science of the Total Environment, 538, 169-179. 
Pall, K., \& Moser, V. (2009). Austrian index macrophytes (AIMmodule 1) for lakes: a water framework directive compliant assessment system for lakes using aquatic macrophytes. Hydrobiologia, 633, 83-104.

Pall, K., Bertrin, V., Buzzi, F., Boutry, S., Dutartre, A., Germ, M., et al. (2014). Alpine lake macrophyte ecological assessment methods. Water Framework Directive Intercalibration Technical Report. Joint Research Centre Technical Reports.

Pall, K., Gecheva, G., Soare-Minea, A., \& Lukacs, B.A. (2016). Eastern continental intercalibration of national-based classification methods for status assessment in lakes. Water Framework Directive Intercalibration Technical Report. Joint Research Centre Technical Reports.

Palmer, M. A., Bell, S. L., \& Butterfield, I. A. (1992). A botanical classification of standing waters in Britain: application for conservation and monitoring. Aquatic Conservation: Marine and Freshwater Ecosystems, 2, 125-143.

Penning, W. E., Dudley, B., Mjelde, M., Hellsten, S., Hanganu, J., Kolada, A., van den Berg, M., Poikane, S., Phillips, G., Willby, N., \& Ecke, F. (2008a). Using aquatic macrophyte community indices to define the ecological status of European lakes. Aquatic Ecology, 42, 253-264.

Penning, W. E., Mjelde, M., Dudley, B., Hellsten, S., Hanganu, J., Kolada, A., van den Berg, M., Poikane, S., Phillips, G., Willby, N., \& Ecke, F. (2008b). Classifying aquatic macrophytes as indicators of eutrophication in European lakes. Aquatic Ecology, 42, 237-251.

Poikane, S., van den Berg, M., Hellsten, S., de Hoyos, C., OrtizCasas, J., Pall, K., Portielje, R., Phillips, G., Solheim, A. L., Tierney, D., Wolfram, G., \& van de Bund, W. (2011). Lake ecological assessment systems and intercalibration for the European water framework directive: aims, achievements and further challenges. Procedia Environmental Sciences, 9, $153-168$

Poikane, S., Birk, S., Bohmer, J., Carvalho, L., de Hoyos, C., Gassner, H., et al. (2015). A hitchhiker's guide to European lake ecological assessment and intercalibration. Ecological Indicators, 52, 533-544.

Portielje, R., Bertrin, V., Denys, L., Grinberga, L., Karottki, I., Kolada, A., et al. (2014). Central Baltic lake macrophyte ecological assessment methods. Water Framework Directive
Intercalibration Technical Report. Joint Research Centre Technical Reports.

Rice, E.W., Baird, R.B., Eaton, A.D., \& Clesceri, L.S. (Eds.) (2012). Standard methods for the examination of water and wastewater. $22^{\text {nd }}$ ed., American Public Health Association, American Water Works Association, Water Environment Federation.

Robertson, D. M., Goddard, G. L., Helsel, D. R., \& MacKinnon, K. L. (2000). Rehabilitation of Delavan lake, Wisconsin. Lake and Reservoir Management, 16, 155-176.

Schaumburg, J., Schranz, C., Hofmann, G., Stelzer, D., Schneider, S., \& Schmedtje, U. (2004). Macrophytes and phytobenthos as indicators of ecological status in German lakes - a contribution to the implementation of the water framework directive. Limnologica - Ecology and Management of Inland Waters, 34, 302-314.

Schneider, S., \& Melzer, A. (2003). The trophic index of macrophytes (TIM) - a new tool for indicating the trophic state of running waters. International Review of Hydrobiology, 88, 49-67.

Sondergaard, M., Johansson, L. S., Lauridsen, T. L., Jorgensen, T. B., Liboriussen, L., \& Jeppesen, E. (2010). Submerged macrophytes as indicators of the ecological quality of lakes. Freshwater Biology, 55, 893-908.

Spoljar, M., Zhang, C., Drazina, T., Zhao, G., \& Lajtner, J. (2017). Development of submerged macrophytes and epiphyton in a flow-through system: assessment and modelling predictions in interconnected reservoirs. Ecological Indicators, 75, 145-154.

Toth, L. G., Poikane, S., Penning, W. E., Free, G., Maemets, H., Kolada, A., \& Hanganu, J. (2008). First steps in the CentralBaltic intercalibration exercise on lake macrophytes: where do we start? Aquatic Ecology, 42, 265-275.

Wang, G. X., Zhang, L. M., Chua, H., Li, X. D., Xia, M. F., \& Pu, P. M. (2009). A mosaic community of macrophytes for the ecological remediation of eutrophic shallow lakes. Ecological Engineering, 35, 582-590.

Willby, N., Pitt, J., \& Phllips, G. (2009). The ecological classification of UK lakes using aquatic macrophytes. Environment agency science report. Project SC010080/R2. Bristol.

XP T90-328 (2010). Water quality-sampling of macrophyte communities in water bodies. 